\title{
The King's Fund and quality of medical care
}

\author{
I. MCCOLL \\ M.S., F.R.C.S. \\ Professor of Surgery, Guy's Hospital Medical School, London SE1 9RT
}

The King's Fund over the years has helped to improve the quality of patient care in numerous ways. For the first 20 years after its foundation it gave grants to improve the London hospitals which had fallen on hard times. The Fund visitors were recruited who regularly undertook the work of inspection. This kind of monitoring was a feature of the Fund from its inception.

In 1911 and 1930 it set up enquiries into the management of Out-Patient Departments and in 1933 published the first Out-Patient Timetable. In 1919 it issued a report drawing attention to the fact that nurses received no pensions and its successful advocacy in this field demonstrated not only its concern for the patients but also for those who served them. It was thought that the quality of care could also be improved by caring for those who looked after the patients.

In the 1930s it became clear that family doctors were spending an inordinate amount of time trying to get their patients admitted to hospitals, and to remedy this situation the Fund established the Emergency Bed Service (E.B.S.) in 1938 and ran this experimental and highly successful project until 1978 when it was taken over by the N.H.S. This is the kind of project in which the King's Fund has always excelled, going into an unsatisfactory managerial problem, sorting it out with an expert organization, making it work and then handing it over for others to run and then focusing attention on some other pressing problem. In 1946 Sir Francis Avery Jones stepped into this splendid organization, which was devoted to improving the quality of patient care, and was an immediate success in furthering the aims of the Fund. He preferred to work behind the scenes, putting forward ideas and content if others took them up and made them their own. He believed in hunting where the natives were friendly and encouraging the converted to do better work, rather than attacking the philistines and trying to compel them to change their ways against their will.

One of his first tasks was to try to improve the quality of hospital food which at that time was more in need of improvement than any other feature of hospital life. With a small committee including catering experts and dietians he re-organized the kitchens of London's hospitals, established a school of catering at St Pancras Hospital and sorted out at least two thirds of all the hospitals. Sir Francis chaired this committee for many years and countless thousands of patients had much better food as a result of his enthusiastic activity. He must have visited more hospital kitchens than any other member of the medical profession. His attention was soon directed to the E.B.S. He became its chairman in 1956 and was always available to give unstintingly of his time and helpful advice and to encourage them by frequent visits.

Sir Francis was instrumental in proposing and establishing the Hospital Centre in London in 1963. This was then situated near Marble Arch and subsequently moved to Camden into an ideally designed building, being renamed the King's Fund Centre. This has proved to be an enormously successful venture and has brought together experts from widely differing fields in the health care world to help to improve the quality of patient care especially among deprived groups such as the elderly and the physically and mentally handicapped. The Centre provides accommodation for a variety of groups specifically founded to help patients in one way or another. For instance it used to house the Spinal Injuries Association, The Child Accident Prevention Trust and the Volunteer Centre which is a national organization to coordinate the whole voluntary effort in health care. It currently accommodates the Centre for Environment for the Handicapped (C.E.H.) which is concerned with improving the environment so that handicapped and elderly people can as individuals make the most of their potential for living and contribute their best to the world about them. In addition the King's Fund Centre provides excellent conference facilities which are in constant use with the aim in view of improving the quality of 
care, not only for patients in hospitals but for patients and people in the community.

In 1958 the Fund set up an Equipment Advisory Service which helped hospitals to decide on the best buy of various items of equipment such as bedside lockers, operating tables etc. In the same year the Fund issued a report on noise control in hospitals and followed this up with a poster campaign in 1962 and 1963.

Perhaps one of the best known features of the Fund is the King's Fund Bed. As Chairman of the King's Fund Centre Committee Sir Francis played a large part in the late 60s developing the specification for the most suitable bed, and any hospital bed which matches this specification can call it a King's Fund Bed. Having established this project it was then handed over to the D.H.S.S. Understandably many people began to think that the main function of the Fund was to manufacture hospital beds!

Sir Francis was convinced that an important way to improve patient care was to improve medical records. In a scholarly review of the subject published in $\mathbf{1 9 7 5}$ he pointed out how essential good records are in order to assist clinical decisions in diagnosis and treatment as well as being essential for good clinical and epidemiological research, assessment of medical care and in promoting good communication of information within hospitals and between hospitals and family practice. He drew attention to their importance in medical education, medical audit and the planning of health care services and made a special plea that medical records should steadily increase in stature but not in girth! He became enamoured of the problem-orientated medical record as a more orderly, sequential and logical method of note taking with its problem list in the front, acting as an efficient index.

Under his influence not only were substantial grants made to Guy's and the Royal Free Hospitals to help establish this system but he kept a helpful and fatherly eye on their progress over several years. In keeping with the Fund's tradition the grants were given on condition that an attempt was made to find out if changing the note system actually improved the quality of care given to patients. This quality was measured at Guy's Hospital for the year before the records were changed and for the year after the change. Similar measurements were made at two other control hospitals and a trend of improvement was detected at Guy's but not at the control hospitals. The introduction of the new notes system also facilitated the training of students and junior medical staff. His approach to peer review or medical audit or quality assurance was rightly cautious preferring gradual evolution to revolution.

He distinguished easily between clear cut issues, like the necessity for improving food in hospitals where he simply went straight ahead and made th necessary changes, and issues which were not so cleát cut where he proceeded with caution. So with the medical records project he was able to achieve two goals in one. He improved medical records and was able to stimulate clinicians to try to measure the quality of care in a more systematic fashion. He carried this further by securing the services of $a$ former President of the Royal College of Physicians Sir Cyril Clarke, to form a Medical Services Study Unit to examine mortality rates in various diseases. This confidential enquiry was another helpful step o $\overrightarrow{0}$ the way forward to helping more clinicians to loof more carefully at the results of treatment.

With his efforts the Department of Communit Health, University of Nottingham, was commis sioned to produce a Gazetteer called Innovations Medical Records in the United Kingdom. One-huto dred and thirty-two different projects were identified their salient details set out and visits made to many of the centres involved. In addition it gave a historica background and a full list of publications. Most hospitals have a small medical records sub-commio tee and this Gazetteer gave them information abour what was going on elsewhere and whether or not might be applicable to them. It was also usefub family doctors as many of the studies relatef general practice records giving them ready access developments which might be of special interest. Othe work led to several useful conferences at the Kings Fund Centre and the whole venture has prove highly successful and has stimulated much intere and further activity around the country.

Dissatisfaction with the small (Lloyd George envelope used in general practice to house the patients' records has mounted in recent years and there has been an increasing appreciation of the nee to change over to a larger A4 size as used in hospitals: This move was early supported by the D.H.S.S. bu unfortunately was an early casualty of the economy drives. Sir Francis was instrumental in a grant being made to a general practice in Suffolk to introduce a interesting modification incorporating the A4 size records and also a number of practices were given 500 grants to enable each to make the initial steps in changing to the new system.

Sir Francis was aware that very little recognitio had been given to the useful work of the Associatiogs of Health Care Information and Medical Records Officers and he arranged for a special grant to be made for them for a work role study. The Medical Records Officers were the cinderellas of the NHS with depleted staffs, cramped accommodation and were constantly being pressed for more and more statistical data. Their career structure seemed inade? quate and they lacked academic support: neverthe less they had done much themselves to help maintaif 
good standards and publish their own journal. Sir Francis felt that they deserved moral and practical support from the Fund in order to benefit the quality of care given to patients.

Sir Francis has served the Fund quietly for 35 years with enthusiasm, boundless energy, humility and a great sense of humour. He has improved the quality of patient care by helping to make access to hospital easier and then providing a more comfortable bed in a quieter environment and better food. He has promoted better medical care by improving the medical records and making medical staff more aware of ways of improving treatment. What better testimony to this radical physician who is content to move quietly behind the scenes. 